\title{
Extended-Spectrum Beta-Lactamase-Producing Enterobacteriaceae in Fresh Produce
}

\author{
Alberto Pintor-Cora, Laura Álvaro-Llorente $\mathbb{D}^{\text {, }}$ Andrés Otero, Jose M. Rodríguez-Calleja (D) and Jesús A. Santos *(D) \\ Department of Food Hygiene and Food Technology, Veterinary Faculty, Universidad de León, 24071 León, Spain \\ apintc@unileon.es (A.P.-C.); lalvl@unileon.es (L.Á.-L.); aotec@unileon.es (A.O.); jm.rcalleja@unileon.es (J.M.R.-C.) \\ * Correspondence: j.santos@unileon.es; Tel.: +34-987-291-249
}

check for

updates

Citation: Pintor-Cora, A.;

Álvaro-Llorente, L.; Otero, A.;

Rodríguez-Calleja, J.M.; Santos, J.A.

Extended-Spectrum Beta-Lactamase-

Producing Enterobacteriaceae in Fresh

Produce. Foods 2021, 10, 2609.

https://doi.org/10.3390/foods 10112609

Academic Editors: Ana Allende and Catherine Burgess

Received: 30 September 2021

Accepted: 25 October 2021

Published: 28 October 2021

Publisher's Note: MDPI stays neutra with regard to jurisdictional claims in published maps and institutional affiliations.

Copyright: (c) 2021 by the authors. Licensee MDPI, Basel, Switzerland. This article is an open access article distributed under the terms and conditions of the Creative Commons Attribution (CC BY) license (https:// creativecommons.org/licenses/by/ $4.0 /)$.

\begin{abstract}
Fresh vegetables are an essential part of a healthy diet, but microbial contamination of fruits and vegetables is a serious concern to human health, not only for the presence of foodborne pathogens but because they can be a vehicle for the transmission of antibiotic-resistant bacteria. This work aimed to investigate the importance of fresh produce in the transmission of extended-spectrum $\beta$-lactamases (ESBL)-producing Enterobacteriaceae. A total of 174 samples of vegetables (117) and farm environment (57) were analysed to determine enterobacterial contamination and presence of ESBLproducing Enterobacteriaceae. Enterobacterial counts above the detection limit were found in $82.9 \%$ vegetable samples and $36.8 \%$ environmental samples. The average count was $4.2 \mathrm{log} \mathrm{cfu} / \mathrm{g}$ or $\mathrm{mL}$, with a maximum value of $6.2 \mathrm{log} \mathrm{cfu} / \mathrm{g}$ in a parsley sample. Leafy vegetables showed statistically significant higher mean counts than other vegetables. A total of 15 ESBL-producing isolates were obtained from vegetables (14) and water (1) samples and were identified as Serratia fonticola (11) and Rahnella aquatilis (4). Five isolates of $S$. fonticola were considered multi-drug resistant. Even though their implication in human infections is rare, they can become an environmental reservoir of antibiotic-resistance genes that can be further disseminated along the food chain.
\end{abstract}

Keywords: vegetables; ESBL-producing Enterobacteriaceae; Serratia fonticola; Rahnella aquatilis

\section{Introduction}

Consumption of fresh produce has risen worldwide as consumers grow interested in their nutritional values and their association with a healthy diet; thus the World Health Organization advises a daily intake of at least $400 \mathrm{~g}$ of fruit and vegetables. At the same time, microbial load of fruits and vegetables is a serious concern to human health, since a large portion of foods of plant origin are consumed raw, with a growing number of foodborne outbreaks linked to fresh produce [1-3]. Besides contributing to the spread of foodborne pathogens, an additional health concern is that vegetables represent a vehicle for the transfer of antibiotic-resistant bacteria or antimicrobial resistance genes to humans, which may occur through the consumption of contaminated fresh produce [4,5]. Recently, the European Food Safety Authority assessed the importance of several food-producing environments in the EU, including plant-based food production, in the emergence and spread of antimicrobial resistance [6]. This Scientific Opinion points to faecal microbial contamination of fertilisers, water and the production environment as specific interventions to minimise bacteria, such as carbapenem-resistant or extended-spectrum cephalosporin-resistant Enterobacteriaceae. Moreover, the report recognises the multiple data gaps as evidencing the importance of transmission routes leading to contamination with antibiotic-resistant bacteria at primary production and post-harvest stages of food-producing systems [6].

Extended-spectrum $\beta$-lactamases (ESBL) are enzymes conferring resistance to a great number of $\beta$-lactam antibiotics and there is an increased prevalence of members of the family Enterobacteriaceae producing ESBL, not only nosocomial, but also in the community $[7,8]$. The presence of ESBL-producing bacteria in vegetables has been reported 
in several studies [9-14] though the results are diverse, from the total absence of ESBLproducing bacteria [9] to isolation rates of $15 \%$ [10].

The order Enterobacterales, in which the family Enterobacteriaceae is included, has undergone a recent major revision [15], with the description of six additional new families. Throughout this work, the references to species of the family Enterobacteriaceae follow the former taxonomic outline defined in the last edition Bergey's Manual [16].

Therefore, the aims of this work were to determine the importance of raw vegetables for direct human consumption as vehicles of extended-spectrum beta-lactamase-producing Enterobacteriaceae and their potential as environmental sources of contamination.

\section{Materials and Methods}

\subsection{Sample Collection and Processing}

A total of 117 samples of fresh vegetables were collected from two conventional farms, one organic farm and from a street market. All the vegetables were from Spain. Samples were of lettuce (Lactuca sativa, $n=23$ ), tomato (Solanum lycopersicum, $n=19$ ), cucumber (Cucumis sativus, $n=19$ ), carrot (Daucus carota subsp. sativus, $n=18$ ), escarole (Cichorium endivia var. latifolium, $n=13$ ), pepper (Capsicum annuum, $n=10$ ), parsley (Petroselinum crispum, $n=9$ ) and coriander (Coriandrum sativum, $n=6$ ). Fifty-seven additional samples from soil $(n=18)$, water $(n=14)$ and air $(n=13)$, as well as from the hands of farm workers $(n=12)$, were also taken in the farms.

Vegetables were lightly cleaned to remove foreign matter and nonedible parts were cut using sterile tools. Ten grams of each vegetable and soil sample were homogenised with $90 \mathrm{~mL}$ of buffered peptone water (BPW; Oxoid, Thermofisher, UK). Water samples were processed by filtering $100 \mathrm{~mL}$ of the sample through a $0.45 \mu \mathrm{m}$ filter and soaking the filter in $100 \mathrm{~mL}$ of BPW. A volume of $100 \mathrm{~L}$ air-sample was collected in farms using a microbial air sampler (Biotest Hycon, Dreieich, Germany) fitted with a ChromAgar Enterobacteria plate (ChromAgar, Paris, France). One hand swab sample was taken from each farm worker, which was then soaked in a $10 \mathrm{~mL}$ of BPW tube.

BPW homogenates were diluted 1:10 in 0.1\% peptone (Oxoid) and appropriate ten-fold dilutions were spread onto ChromAgar Enterobacteria plates (ChromAgar) and incubated at $37^{\circ} \mathrm{C}$ for $24 \mathrm{~h}$. Pink/reddish colonies were recorded as suspected Enterobacteriaceae and blue ones as suspected E. coli.

The remaining homogenates were incubated for $24 \mathrm{~h}$ at $37^{\circ} \mathrm{C}$. One loopful of the enriched solution was streaked onto ChromAgar ESBL (ChromAgar) plates for the isolation of ESBL-producing bacteria. Plates were incubated at $37^{\circ} \mathrm{C}$ for $24 \mathrm{~h}$ and colonies with morphology associated with $\beta$-lactam resistance were selected for further characterisation.

\subsection{Matrix-Assisted Laser Desorption Ionisation Time-of-Flight (MALDI-TOF) Identification of Isolates}

The isolates were grown on Tryptone Soya Agar (TSA) plates (Oxoid) for 16-24 h at $37^{\circ} \mathrm{C}$. Colony material was collected with a sterile pipette tip and smeared as a thin film on a MALDI target plate. After air drying, each sample was overlaid with $1 \mu \mathrm{L}$ of the matrix solution ( $\alpha$-Cyano-4-hydroxycinnamic acid, CHCA) and allowed to dry. Spectra were acquired with the MALDI Biotyper system (Bruker Daltonik, Bremer, Germany) and compared with the reference database (Bruker Daltonik).

\subsection{Antimicrobial Susceptibility Testing}

MAST D72C AmpC and ESBL detection kit (MAST group, UK) was used for ESBL confirmation. Equivocal results were confirmed using the combination disk diffusion test following the indications of EUCAST (https:/ / eucast.org/; accessed on 29 September 2021). In addition, representative isolates were selected to determine minimum inhibitory concentration (MIC) by microdilution using Sensititre EUVSEC2 plates (Thermofisher, UK) with the following antimicrobials: cefoxitin, cefotaxime, cefotaxime/clavulanic acid, cef- 
tazidime, ceftazidime/clavulanic acid, cefepime, ertapenem, imipenem, meropenem and temocillin. MIC interpretation was carried out according to EUCAST cutoff values.

E. coli CECT 434 was used as a negative control, while E. coli M1L9c was used as positive control for ESBL production.

The detection of multidrug-resistant (MDR) isolates was carried out using a selection of antimicrobial agents of different categories, according to the proposal of the European Centre for Disease Prevention and Control and the Centers for Disease Control and Prevention [17]. The antimicrobial agents were ampicillin, cefuroxime, cefotaxime, cefepime, aztreonam, imipenem, gentamicin, ciprofloxacin, trimethoprim-sulphamethoxazole and chloramphenicol [17].

\subsection{PCR Detection and Characterisation of ESBL-Associated Genes}

The presence of $b l a_{T E M}, b l a_{S H V}$ and $b l a_{C T X-M}$ genes in phenotypically confirmed ESBLproducing isolates was checked by PCR using the primers and conditions described elsewhere [18] (Supplementary Table S1).

Amplified products were purified and both strands were sequenced in a MegaBACE 500 sequencer (GE Healthcare Life Sciences, UK). DNA sequences were compared with curated sequences contained in the Bacterial Antimicrobial Resistance Reference Gene Database (https:/ / www.ncbi.nlm.nih.gov/bioproject/PRJNA313047; accessed on 29 September 2021).

\subsection{Data Analysis}

Enterobacteriaceae and E. coli counts were transformed and expressed as $\log \mathrm{cfu} / \mathrm{mL}$ or $\log \mathrm{cfu} / \mathrm{g}$. Descriptive statistics of each count (mean, standard deviation, minimum and maximum) were calculated and, for each value of the agricultural groups (sample type, sample group, origin, and agricultural practices), normality/no normality assumptions about bacterial population distributions were examined. The Kruskal-Wallis one-factor ANOVA and the Mann-Whitney U procedure were used for testing the mean difference in counts among the groups and to determine their relationships. Subsequently, the nonparametric Kruskal-Wallis test was conducted for post-hoc pairwise comparisons on all possible pairwise contrasts. The IBM SPSS Statistics for Windows, Version 26.0 (IBM Corp., Armonk, NY, USA) program was used for data analysis.

\section{Results}

\subsection{Enterobacteriaceae and E. coli Counts}

Enterobacterial counts above the detection limit of $2 \log \mathrm{cfu} / \mathrm{g}$ for vegetables and soil, and $1 \mathrm{cfu}$ for sample volume for air, water and hands of workers were found in $97(82.9 \%)$ vegetable samples and 21 (36.8\%) environmental samples. The average count was $4.2 \mathrm{log}$ $\mathrm{cfu} / \mathrm{g}$ or $\mathrm{mL}$, with a maximum value of $6.2 \mathrm{log} \mathrm{cfu} / \mathrm{g}$ in a parsley sample. Leafy vegetables (lettuce, escarole, parsley and coriander) showed statistically significant $(p<0.05)$ higher mean counts than other vegetables (Table 1).

Twenty-nine (16.7\%) samples presented counts of E. coli above the limit of detection, all but one obtained from vegetables, with an average value of $2.3 \mathrm{log} \mathrm{cfu} / \mathrm{g}$; five of them showed values higher than $3 \log \mathrm{cfu} / \mathrm{g}$, the upper limit established in the microbiological process hygiene criteria for precut ready-to-eat fruits and vegetables in the EU (Table 1) [19].

\subsection{Isolation of ESBL Strains}

Suspected ESBL isolates were obtained from Chromagar ESBL plates in $31(17.8 \%)$ samples. Most of the suspected samples (26) were of vegetables, 20 of leaf vegetables and 6 of other vegetables. Five environmental samples of water (3), soil (1) and hands of workers (1) carried presumptive isolates. Confirmation with MAST D72C kit resulted in 15 ESBL-producing isolates, 14 from vegetables and 1 from a water sample (Table 2). 
Table 1. Counts (log cfu/g or $\mathrm{mL}$ ) of Enterobacteriaceae and E. coli in vegetables and environmental samples.

\begin{tabular}{|c|c|c|c|c|}
\hline & & $n$ & Enterobacteriaceae Counts ${ }^{1}$ & E. coli Counts ${ }^{1}$ \\
\hline & Lettuce & 23 & $4.1 \pm 1.1(19)$ & $2.7 \pm 1.6(3)$ \\
\hline & Escarole & 13 & $5.4 \pm 0.3(13)$ & $3.0 \pm 0.0(1)$ \\
\hline & Parsley & 9 & $5.3 \pm 0.5(9)$ & $2.4+1.0(5)$ \\
\hline & Coriander & 6 & $5.1 \pm 0.8(6)$ & $1.7 \pm 0.0(4)$ \\
\hline \multirow[t]{5}{*}{ Leaf vegetables } & & 51 & $5.0 \pm 1.0(47)$ & $2.5 \pm 0.9(13)$ \\
\hline & Tomato & 19 & $3.6 \pm 0.8(12)$ & $2.3 \pm 0.9(4)$ \\
\hline & Cucumber & 19 & $3.9 \pm 0.8(11)$ & $1.7 \pm 0.0(3)$ \\
\hline & Pepper & 10 & $3.5 \pm 0.5(10)$ & $2.7 \pm 0.9(4)$ \\
\hline & Carrot & 18 & $4.7 \pm 0.9(17)$ & $1.8 \pm 0.2(4)$ \\
\hline Other vegetables & & 66 & $3.9 \pm 0.9(50)$ & $2.1 \pm 0.8(15)$ \\
\hline \multirow[t]{5}{*}{ Total vegetables } & & 117 & $4.5 \pm 1.0(97)$ & $2.3 \pm 0.8(28)$ \\
\hline & Soil & 18 & $3.3 \pm 0.8(13)$ & -2 \\
\hline & Water & 14 & $3.0 \pm 0.4(6)$ & - \\
\hline & Air & 13 & $0.6 \pm 0.4(4)$ & - \\
\hline & Worker hands & 12 & $3.7 \pm 0.6(2)$ & $2.8 \pm 0.0(1)$ \\
\hline Environmental & & 57 & $2.9 \pm 1.2(21)$ & $2.8 \pm 0.0(1)$ \\
\hline Total & & 174 & $4.1 \pm 1.2(118)$ & $2.3 \pm 0.8(29)$ \\
\hline
\end{tabular}

${ }^{1}$ Average count \pm standard deviation in log cfu/g or mL. In brackets, number of samples showing counts above the detection limit. ${ }^{2}$ Counts below the detection limit ( $2 \log$ CFU/g for vegetables and soil, and 1 cfu for sample volume for air, water and hands of workers).

Table 2. ESBL-producing Enterobacteriaceae isolated from vegetables and farm environment samples.

\begin{tabular}{|c|c|c|c|c|c|}
\hline Isolate & ID & Source & $\begin{array}{c}\text { Antibiotic Resistance } \\
\text { Profiles }{ }^{1}\end{array}$ & MDR & ESBL Gene \\
\hline ZA07E1 & Rahnella aquatilis & Carrot & AMP, CXM, CTX & No & $b l a_{R A H N 2}$ \\
\hline CI03E & Serratia fonticola & Coriander & AMP, CXM & No & $b l a_{F O N A 5}$ \\
\hline CI10E & Serratia fonticola & Coriander & AMP, CXM, CTX, CN & Yes & $b l a_{F O N A 5}$ \\
\hline CI04E1 & Serratia fonticola & Coriander & AMP, CXM, CTX & No & \\
\hline PE11E & Serratia fonticola & Cucumber & $\mathrm{AMP}, \mathrm{CXM}, \mathrm{CN}$ & Yes & \\
\hline ES09E & Serratia fonticola & Escarole & AMP, CXM & No & \\
\hline ES48E & Rahnella aquatilis & Escarole & AMP, CXM, CTX & No & $b l a_{R A H N 2}$ \\
\hline ES16E & Rahnella aquatilis & Escarole & AMP, CXM, CTX & No & \\
\hline LE18E & Serratia fonticola & Lettuce & AMP, CXM, CTX & No & $b l a_{F O N A 5}$ \\
\hline PJ02E & Serratia fonticola & Parsley & AMP, CXM, CTX, FEP, ATM & Yes & \\
\hline PJ07E & Serratia fonticola & Parsley & AMP, CXM, CTX, ATM & Yes & \\
\hline PJ21E & Serratia fonticola & Parsley & AMP, CXM, CTX & No & \\
\hline PJ27E & Serratia fonticola & Parsley & $\mathrm{AMP}, \mathrm{CXM}, \mathrm{CTX}, \mathrm{CN}$ & Yes & $b l a_{F O N A 5}$ \\
\hline TO30E & Rahnella aquatilis & Tomato & AMP, CXM, CTX & No & \\
\hline AG24E & Serratia fonticola & Water & $\mathrm{AMP}, \mathrm{CXM}$ & No & \\
\hline
\end{tabular}

${ }^{1}$ AMP, Ampicillin; CXM, Cefuroxime; CTX, cefotaxime; FEP, cefepime; ATM, aztreonam; CN, gentamicin.

The detection of ESBL-producing bacteria was statistically related $(p<0.05)$ to the concentration of Enterobacteriaceae found in the sample, with a significant effect detected in the samples with Enterobacteriaceae counts above $5 \log \mathrm{cfu} / \mathrm{g}$.

The isolates were identified as Serratia fonticola (11) and Rahnella aquatilis (4).

Genes encoding CTX-M $\beta$-lactamases were detected in six (40\%) isolates, whereas no ESBL-genes were detected with the specified primers in the remaining nine isolates. The ct $x-M$ gene was detected in four isolates of $S$. fonticola and two of $R$. aquatilis, all of them isolated from vegetables. Analysis of sequences revealed that the genes from $S$. fonticola were similar to $b l a_{F O N A 5}$ genes and those from $R$. aquatilis were similar to bla $a_{\text {RHN2 }}$ gene (Table 2). 
Five isolates of $S$. fonticola were resistant to antimicrobial agents of different categories, thus being considered MDR. No isolate was resistant to imipenem, ciprofloxacin, trimethoprim-sulphamethoxazole or chloramphenicol (Table 2).

Five S. fonticola and four $R$. aquatilis isolates representative of the positive samples were selected to determine minimum inhibitory concentrations (MIC). All the isolates showed an intermediate MIC value for temocillin. Three R. aquatilis and one S. fonticola isolate had MICs above the clinical breakpoint for cefotaxime and a reduction greater than two-fold concentration in the presence of clavulanic acid, which could be explained by the presence of ESBL enzymes. The remaining isolates had a detectable MIC value for cefotaxime below the breakpoint, again showing a reduction greater than two-fold in the presence of clavulanic acid. One R. aquatilis and two S. fonticola isolates had MICs above the breakpoint for cefoxitin, and one S. fonticola isolate for cefepime as well (Table 3).

Table 3. Minimum inhibitory concentrations of five S. fonticola and four R. aquatilis isolates.

\begin{tabular}{|c|c|c|c|c|c|c|c|c|c|c|c|c|}
\hline Isolate & ID & Source & $\begin{array}{c}\text { FOX } \\
(0.5-64)\end{array}$ & $\begin{array}{c}\text { FOT } \\
(0.25-64)\end{array}$ & $\begin{array}{c}\mathrm{FC} \\
(0.06 / 4-64 / 4)\end{array}$ & $\begin{array}{c}\text { TAZ } \\
(0.25-128)\end{array}$ & $\begin{array}{c}\text { TC } \\
(0.12 / 4-128 / 4)\end{array}$ & $\begin{array}{c}\text { FEP } \\
(0.06-32)\end{array}$ & $\underset{(0.015-2)}{\text { ETP }}$ & $\begin{array}{c}\text { IMI } \\
(0.12-16)\end{array}$ & $\begin{array}{c}\text { MERO } \\
(0.03-16)\end{array}$ & $\begin{array}{c}\text { TRM } \\
(0.5-128)\end{array}$ \\
\hline ZA07E1 & $\begin{array}{l}\text { Rahnella } \\
\text { aquatillis }\end{array}$ & Carrot & 2 & $4^{*}$ & $<0.06 / 4$ & $<0.25$ & $<0.12 / 4$ & 0.25 & $<0.015$ & $<0.012$ & $<0.03$ & $8^{* *}$ \\
\hline CI03E & $\begin{array}{c}\text { Serratia } \\
\text { fonticola }\end{array}$ & Coriander & 4 & 0.5 & $<0.06 / 4$ & $<0.25$ & $<0.12 / 4$ & $<0.06$ & $<0.015$ & $<0.012$ & $<0.03$ & $4^{* *}$ \\
\hline CI04E1 & $\begin{array}{c}\text { Serratia } \\
\text { fonticola }\end{array}$ & Coriander & $8^{*}$ & 1 & $<0.06 / 4$ & $<0.25$ & $<0.12 / 4$ & $<0.06$ & $<0.015$ & $<0.012$ & $<0.03$ & $8^{* *}$ \\
\hline ES16E & $\begin{array}{l}\text { Rahnella } \\
\text { aquatillis }\end{array}$ & Escarole & 1 & $2 *$ & $<0.06 / 4$ & $<0.25$ & $<0.12 / 4$ & 0.12 & $<0.015$ & $<0.012$ & $<0.03$ & $4^{* *}$ \\
\hline ES48E & $\begin{array}{l}\text { Rahnella } \\
\text { aquatillis }\end{array}$ & Escarole & $8^{*}$ & $2 *$ & $<0.06 / 4$ & $<0.25$ & $<0.12 / 4$ & 0.12 & $<0.015$ & $<0.012$ & $<0.03$ & $4^{* *}$ \\
\hline LE18E & $\begin{array}{c}\text { Serratia } \\
\text { fonticola }\end{array}$ & Lettuce & 2 & 0.5 & $<0.06 / 4$ & $<0.25$ & $<0.12 / 4$ & $<0.06$ & $<0.015$ & $<0.012$ & $<0.03$ & $2 * *$ \\
\hline PJ02E & $\begin{array}{c}\text { Serratia } \\
\text { fonticola }\end{array}$ & Parsley & $16^{*}$ & $>64 *$ & $0.5 / 4$ & 1 & $<0.12 / 4$ & $4^{*}$ & $<0.015$ & $<0.012$ & $<0.03$ & $4^{* *}$ \\
\hline TO30E & $\begin{array}{l}\text { Rahnella } \\
\text { aquatillis }\end{array}$ & Tomato & 0.5 & 1 & $<0.06 / 4$ & $<0.25$ & $<0.12 / 4$ & $<0.06$ & $<0.015$ & $<0.012$ & $<0.03$ & $4^{* *}$ \\
\hline AG24E & $\begin{array}{c}\text { Serratia } \\
\text { fonticola }\end{array}$ & Water & 4 & 0.5 & $<0.06 / 4$ & $<0.25$ & $<0.12 / 4$ & $<0.06$ & $<0.015$ & $<0.012$ & $<0.03$ & $8^{* *}$ \\
\hline
\end{tabular}

FOX, cefoxitin; FOT, cefotaxime; FC, cefotaxime/clavulanic acid; TAZ, ceftazidime; TC, ceftazidime/clavulanic acid; FEP, cefepime; ETP, ertapenem; IMI, imipenem; MERO, meropenem; TRM, temocillin. * Above the resistance breakpoint. ** Intermediate value between susceptible and resistant breakpoint.

\section{Discussion}

Enterobacteriaceae and E. coli counts are used as indicators of faecal contamination and lack of hygiene during food production, but there is a growing concern as many strains are becoming resistant to antibiotics used to treat human infections, such as carbapenems or colistin [20]. The results obtained in this study show that ready-to-eat fresh produce, especially leaf vegetables, presented high counts of Enterobacteriaceae and, to a lesser extent, of E. coli. The results are in accordance with similar works, thus Falomir et al. [21] detected coliforms counts in $50 \%$ of vegetable samples, carrot and lettuce being the most contaminated, suggesting the probability of contact with a source of contamination (soil, water, manure) during growth [14,22]. In another study, Mukherjee et al. [23] reported an overall prevalence of $E$. coli of $8 \%$ positive samples, being higher in leaf vegetables but lower than the prevalence found by us (16.7\%), and an average count of $3.1 \log$ MPN/g ( $2.3 \mathrm{cfu} / \mathrm{g}$ in our study). The environmental sample showing E. coli counts was taken from the hands of a farm worker, highlighting the importance of good food hygiene in reducing the microbial load of ready-to-eat foods [24,25].

The isolation of ESBL-producing Enterobacteriaceae in vegetable samples in this study confirmed previous reports that pointed to vegetables as a vehicle of dissemination of resistance genes [10-14]. The detection of ESBL-producing bacteria was related to Enterobacteriaceae counts, indicating that routine monitoring of this bacterial group in fresh produce is a good indicator both of hygiene quality and presence of antibiotic-resistant bacteria.

The isolates were identified as Serratia fonticola and Rahnella aquatilis. Antibioticresistant S. fonticola and R. aquatilis have been found in vegetables and farm environments $[10,12,26-29]$ and their presence is considered of minor importance from a health 
point of view, as they are linked to human diseases in rare instances [30,31]. However, they can be the source of resistant genes which can be transferred to other bacteria causing human infections [32]. In addition, the ingestion of nonpathogenic ESBL-producing bacteria may result in potential intestinal horizontal gene transfer to pathogens [33]. It is important to keep in mind that the plasmid-encoded SFO-1 ESBL produced by Enterobacer cloacae is derived from the FONA enzyme of $S$. fonticola and has been observed in hospital outbreaks of infection in Spain [34,35]. Furthermore, the detection of MDR among S. fonticola isolates is an additional concern as other reports detected no MDR S. fonticola in vegetable samples [27] and a review of clinical cases of $S$. fonticola infections reported susceptibility to cefepime and gentamicin among the strains tested [36], whereas resistance to both antimicrobials was found in this study, indicating a recent acquisition of resistance to those agents. A recent report isolated a multidrug-resistant strain from a patient with a biliary tract infection [37], highlighting the relevance of dissemination of resistance genes among opportunistic bacteria.

As S. fonticola and R. aquatilis are considered environmental Enterobacteriaceae, irrigation water and soil are the probable route of contamination of vegetables, as suggested by other authors $[10,14,38]$.

In conclusion, ESBL-producing S. fonticola and R. aquatilis are environmental Enterobacteriaceae commonly found in vegetables and other food commodities. Even though their implication in human infections is rare, they can become an environmental reservoir of antibiotic-resistant genes that can be further disseminated along the food chain.

Supplementary Materials: The following are available online at https: / www.mdpi.com/article / 10.3390 / foods10112609/s1, Table S1: Primers and conditions used for PCR amplification of bla $a_{T E M}$, $b_{S H V}$, and $b l a_{C T X-M}$ genes.

Author Contributions: Conceptualisation, A.O., J.M.R.-C. and J.A.S.; methodology, A.P.-C. and L.Á.-L.; software, A.P.-C., J.M.R.-C. and J.A.S.; investigation, A.P-C., L.Á.-L., A.O., J.M.R.-C. and J.A.S.; writing—original draft preparation, A.P.-C., J.M.R.-C. and J.A.S.; writing-review and editing, all the authors; project administration, J.M.R.-C. and J.A.S.; funding acquisition, J.M.R.-C. and J.A.S. All authors have read and agreed to the published version of the manuscript.

Funding: This research was funded by “Agencia Estatal de Investigación” (Spanish R\&D Program; project PID2019-107870RB-I00 EI/10.13039/5011000111033). A.P.-C. benefits from a predoctoral contract from the Universidad de León. L.Á.-L. thanks the program for youth employment in research (Consejería de Educación, Junta de Castilla y León and FEDER).

Conflicts of Interest: The authors declare no conflict of interest.

\section{References}

1. Callejón, R.M.; Rodríguez-Naranjo, M.I.; Ubeda, C.; Hornedo-Ortega, R.; Garcia-Parrilla, M.C.; Troncoso, A.M. Reported Foodborne Outbreaks Due to Fresh Produce in the United States and European Union: Trends and Causes. Foodborne Pathog. Dis. 2015, 12, 32-38. [CrossRef] [PubMed]

2. Olaimat, A.N.; Holley, R.A. Factors influencing the microbial safety of fresh produce: A review. Food Microbiol. 2012, 32, 1-19. [CrossRef]

3. FAO/WHO. Microbiological Hazards in Fresh Leafy Vegetables and Herbs: Meeting Report; Microbiological Risk Assessment Series 14; FAO: Rome, Italy, 2008; ISBN 978-92-4-156378-9.

4. Verraes, C.; Van Boxstael, S.; Van Meervenne, E.; Van Coillie, E.; Butaye, P.; Catry, B.; de Schaetzen, M.A.; Van Huffel, X.; Imberechts, H.; Dierick, K.; et al. Antimicrobial resistance in the food chain: A review. Int. J. Environ. Res. Public Health 2013, 10, 2643-2669. [CrossRef]

5. Hudson, J.A.; Frewer, L.J.; Jones, G.; Brereton, P.A.; Whittingham, M.J.; Stewart, G. The agri-food chain and antimicrobial resistance: A review. Trends Food Sci. Technol. 2017, 69, 131-147. [CrossRef]

6. EFSA BIOHAZ Panel. Role played by the environment in the emergence and spread of antimicrobial resistance (AMR) through the food chain. EFSA J. 2021, 19, 6651.

7. Bradford, P.A. Extended-spectrum $\beta$-lactamases in the 21st century: Characterization, epidemiology, and detection of this important resistance threat. Clin. Microbiol. Rev. 2001, 14, 933-951. [CrossRef] [PubMed]

8. Cantón, R.; Novais, A.; Valverde, A.; Machado, E.; Peixe, L.; Baquero, F.; Coque, T.M. Prevalence and spread of extended-spectrum $\beta$-lactamase-producing Enterobacteriaceae in Europe. Clin. Microbiol. Infect. 2008, 14, 144-153. [CrossRef] 
9. Randall, L.P.; Lodge, M.P.; Elviss, N.C.; Lemma, F.L.; Hopkins, K.L.; Teale, C.J.; Woodford, N. Evaluation of meat, fruit and vegetables from retail stores in five United Kingdom regions as sources of extended-spectrum beta-lactamase (ESBL)-producing and carbapenem-resistant Escherichia coli. Int. J. Food Microbiol. 2017, 241, 283-290. [CrossRef]

10. Blaak, H.; van Hoek, A.H.A.M.; Veenman, C.; Docters van Leeuwen, A.E.; Lynch, G.; van Overbeek, W.M.; de Roda Husman, A.M. Extended spectrum B-lactamase- and constitutively AmpC-producing Enterobacteriaceae on fresh produce and in the agricultural environment. Int. J. Food Microbiol. 2014, 168-169, 8-16. [CrossRef]

11. van Hoek, A.H.A.M.; Veenman, C.; van Overbeek, W.M.; Lynch, G.; de Roda Husman, A.M.; Blaak, H. Prevalence and characterization of ESBL- and AmpC-producing Enterobacteriaceae on retail vegetables. Int. J. Food Microbiol. 2015, 204, 1-8. [CrossRef]

12. Raphael, E.; Wong, L.K.; Riley, L.W. Extended-spectrum beta-lactamase gene sequences in Gram-negative saprophytes on retail organic and nonorganic spinach. Appl. Environ. Microbiol. 2011, 77, 1601-1607. [CrossRef]

13. Reuland, E.A.; Al Naiemi, N.; Raadsen, S.A.; Savelkoul, P.H.M.; Kluytmans, J.A.J.W.; Vandenbroucke-Grauls, C.M.J.E. Prevalence of ESBL-producing Enterobacteriaceae in raw vegetables. Eur. J. Clin. Microbiol. Infect. Dis. 2014, 33, 1843-1846. [CrossRef]

14. Ruimy, R.; Brisabois, A.; Bernede, C.; Skurnik, D.; Barnat, S.; Arlet, G.; Momcilovic, S.; Elbaz, S.; Moury, F.; Vibet, M.A.; et al. Organic and conventional fruits and vegetables contain equivalent counts of Gram-negative bacteria expressing resistance to antibacterial agents. Environ. Microbiol. 2010, 12, 608-615. [CrossRef]

15. Adeolu, M.; Alnajar, S.; Naushad, S.; Gupta, R.S. Genome-based phylogeny and taxonomy of the 'Enterobacteriales': Proposal for Enterobacterales ord. nov. divided into the families Enterobacteriaceae, Erwiniaceae fam. nov., Pectobacteriaceae fam. nov., Yersiniaceae fam. nov., Hafniaceae fam. nov., Morganellaceae fam. nov., and Budviciaceae fam. nov. Int. J. Syst. Evol. Microbiol. 2016, 66, 5575-5599.

16. Brenner, D.J.; Farmer III, J.J. Enterobacteriaceae. In Bergey's Manual of Systematics of Archaea and Bacteria; Trujillo, M.E., Dedysh, S., DeVos, P., Hedlund, B., Kämpfer, P., Rainey, F.A., Whitman, W.B., Eds.; John Wiley \& Sons, Ltd.: Hoboken, NJ, USA, 2015; pp. 1-24. ISBN 9781118960608.

17. Magiorakos, A.P.; Srinivasan, A.; Carey, R.B.; Carmeli, Y.; Falagas, M.E.; Giske, C.G.; Harbarth, S.; Hindler, J.F.; Kahlmeter, G.; Olsson-Liljequist, B.; et al. Multidrug-resistant, extensively drug-resistant and pandrug-resistant bacteria: An international expert proposal for interim standard definitions for acquired resistance. Clin. Microbiol. Infect. 2012, 18, 268-281. [CrossRef] [PubMed]

18. Monstein, H.J.; Östholm-Balkhed, Å.; Nilsson, M.V.; Nilsson, M.; Dornbusch, K.; Nilsson, L.E. Multiplex PCR amplification assay for the detection of blaSHV, blaTEM and blaCTX-M genes in Enterobacteriaceae. APMIS 2007, 115, 1400-1408. [CrossRef]

19. European Commission. Commission Regulation (EC) No 2073/2005 of 15 November 2005 on microbiological criteria for foodstuffs. Off. J. Eur. Union 2005, L338, 1-26.

20. EFSA BIOHAZ Panel. Scientific Opinion on the public health risks of bacterial strains producing extended-spectrum $\beta$-lactamases and/or AmpC $\beta$-lactamases in food and food-producing animals. EFSA J. 2011, 9, 2322. [CrossRef]

21. Falomir, M.P.; Gozalbo, D.; Rico, H. Coliform bacteria in fresh vegetables: From cultivated lands to consumers. In Current Research Topics in Applied Microbiology and Microbial Biotechnology, Proceedings of the II International Conference on Environmental, Industrial and Applied Microbiology (BioMicroWorld2007); Seville, Spain, 28 November-1 December 2007, Méndez-Vilas, A., Ed.; World Scientific: Hackensack, NJ, USA, 2010; pp. 1175-1181.

22. Falomir, P.; González, P.; Rico, H.; Gozalbo, D. Resistances to Chemotherapeutic Agents in Enterobacteriaceae Isolates from Organic Fresh Vegetables Marketed in Valencia (Spain). Int. J. Food Nutr. Saf. 2014, 5, 39-49.

23. Mukherjee, A.; Speh, D.; Dyck, E.; Diez-Gonzalez, F. Preharvest evaluation of coliforms, Escherichia coli, Salmonella, and Escherichia coli O157:H7 in organic and conventional produce grown by Minnesota farmers. J. Food Prot. 2004, 67, 894-900. [CrossRef]

24. Little, C.L.; Gillespie, I.A. Prepared salads and public health. J. Appl. Microbiol. 2008, 105, 1729-1743. [CrossRef] [PubMed]

25. Meldrum, R.J.; Little, C.L.; Sagoo, S.; Mithani, V.; McLauchlin, J.; de Pinna, E. Assessment of the microbiological safety of salad vegetables and sauces from kebab take-away restaurants in the United Kingdom. Food Microbiol. 2009, 26, 573-577. [CrossRef] [PubMed]

26. Ruimy, R.; Meziane-Cherif, D.; Momcilovic, S.; Arlet, G.; Andremont, A.; Courvalin, P. RAHN-2, a chromosomal extendedspectrum class A $\beta$-lactamase from Rahnella aquatilis. J. Antimicrob. Chemother. 2010, 65, 1619-1623. [CrossRef] [PubMed]

27. Nüesch-Inderbinen, M.; Zurfluh, K.; Peterhans, S.; Hächler, H.; Stephan, R. Assessment of the prevalence of extended-spectrum $\beta$-lactamase-producing Enterobacteriaceae in ready-to-eat salads, fresh-cut fruit, and sprouts from the Swiss market. J. Food Prot. 2015, 78, 1178-1181. [CrossRef] [PubMed]

28. Richter, L.; Du Plessis, E.M.; Duvenage, S.; Korsten, L. Occurrence, identification, and antimicrobial resistance profiles of extended-spectrum and AmpC $\beta$-lactamase-producing Enterobacteriaceae from fresh vegetables retailed in Gauteng Province, South Africa. Foodborne Pathog. Dis. 2019, 16, 421-427. [CrossRef]

29. Richter, L.; du Plessis, E.M.; Duvenage, S.; Korsten, L. Occurrence, Phenotypic and Molecular Characterization of ExtendedSpectrum- and AmpC- $\beta$-Lactamase Producing Enterobacteriaceae Isolated From Selected Commercial Spinach Supply Chains in South Africa. Front. Microbiol. 2020, 11, 638. [CrossRef]

30. Bollet, C.; Gainnier, M.; Sainty, J.M.; Orhesser, P.; De Micco, P. Serratia fonticola isolated from a leg abscess. J. Clin. Microbiol. 1991, 29, 834. [CrossRef]

31. Gaitán, J.I.; Bronze, M.S. Infection caused by Rahnella aquatilis. Am. J. Med. Sci. 2010, 339, 577-579. [CrossRef] 
32. Cantón, R.; Coque, T.M. The CTX-M $\beta$-lactamase pandemic. Curr. Opin. Microbiol. 2006, 9, 466-475. [CrossRef] [PubMed]

33. Huddleston, J.R. Horizontal gene transfer in the human gastrointestinal tract: Potential spread of antibiotic resistance genes. Infect. Drug Resist. 2014, 7, 167-176. [CrossRef]

34. Matsumoto, Y.; Inoue, M. Characterization of SFO-1, a plasmid-mediated inducible class A $\beta$-lactamase from Enterobacter cloacae. Antimicrob. Agents Chemother. 1999, 43, 307-313. [CrossRef]

35. Fernández, A.; Pereira, M.J.; Suárez, J.M.; Poza, M.; Treviño, M.; Villalón, P.; Sáez-Nieto, J.A.; Regueiro, B.J.; Villanueva, R.; Bou, G. Emergence in Spain of a multidrug-resistant Enterobacter cloacae clinical isolate producing SFO-1 extended-spectrum $\beta$-lactamase. J. Clin. Microbiol. 2011, 49, 822-828. [CrossRef]

36. Aljorayid, A.; Viau, R.; Castellino, L.; Jump, R.L.P. Serratia fonticola, pathogen or bystander? A case series and review of the literature. IDCases 2016, 5, 6-8. [CrossRef] [PubMed]

37. Hai, P.D.; Hoa, L.T.V.; Tot, N.H.; Phuong, L.L.; Quang, V.V.; Thuyet, B.T.; Son, P.N. First report of biliary tract infection caused by multidrug-resistant Serratia fonticola. New Microbes New Infect. 2020, 36, 100692. [CrossRef] [PubMed]

38. Tacão, M.; Correia, A.; Henriques, I. Resistance to broad-spectrum antibiotics in aquatic systems: Anthropogenic activities modulate the dissemination of blaCTX-M-like genes. Appl. Environ. Microbiol. 2012, 78, 4134-4140. [CrossRef] [PubMed] 